\title{
Comparative study of abnormal placentation in patients with previous two caesarean section over two time periods
}

\author{
Supria Poonia*, Nihita Pandey, Alka Gupta
}

\begin{abstract}
Department of Obstetrics and Gynaecology, Seth Gordhandas Sunderdas Medical College and King Edward VII Memorial Hospital, Mumbai, Maharashtra, India
\end{abstract}

Received: 26 August 2016

Accepted: 26 September 2016

*Correspondence:

Dr. Supria Poonia,

E-mail: supriyachaudhary01@gmail.com

Copyright: (C) the author(s), publisher and licensee Medip Academy. This is an open-access article distributed under the terms of the Creative Commons Attribution Non-Commercial License, which permits unrestricted non-commercial use, distribution, and reproduction in any medium, provided the original work is properly cited.

\begin{abstract}
Background: The CS epidemic is a reason for immediate concern and there is increase in repeat CS as well these days. The secondary increase in repeat CS delivery has been associated with increase in CS complications particularly increase in complications associated with abnormal placentation. We aim to compare the change in rate of abnormal placentation i.e. placenta previa, placenta percreta and accreta and maternal and fetal outcomes associated with two or more caesarean sections.

Methods: Women with previous two LSCS were studied from May 2003-May 2004 and again from May 2013- May 2014. It is a comparative analysis of two prospective observational studies where the rate of abnormal placentation and maternal and fetal outcomes were compared after a period of ten years in the same tertiary care institute.

Results: 104 women (0.99\% of total confinements) had previous two or more LSCS from May 2003-04 (Group 1), whereas 60 such women $(0.75 \%$ of total confinements) were there from May 2013-14 (Group 2). There was $2.88 \%$ incidence of abnormal placentation in Group 1 as compared to $18.33 \%$ in Group 2. The modality of management in Group 1 for adherent placenta was obstetric hysterectomy whereas conservative approach was increasingly used in Group 2. There were no maternal or neonatal deaths.

Conclusions: Morbidly adherent placenta although on the increase can be increasingly tackled by conservative means. A multi-disciplinary approach is imperative to reduce maternal morbidity and mortality.
\end{abstract}

Keywords: Abnormal placentation, Maternal and fetal outcomes, Two or more caesarean sections

\section{INTRODUCTION}

The increase in caesarean section is a global phenomenon and is accepted amongst one of many advances in obstetrics practise. From the times when child birth was just another routine event in a woman's life to present day when pregnancy requires immediate obstetrician attention, obstetrics has travelled a long way. The rise in caesarean section rate has led to increase in complications which have a negative impact on maternal and child health.
With the advent of safety of lower segment caesarean section, availability of blood and blood products, powerful and effective antibiotics, evolution in anaesthetic proficiency, improvement in surgical techniques, recognition of fetus as a patient, advances in fetal surveillance and broadening of indications of caesarean section, caesarean section have characterised the evolution of this procedure in $21^{\text {st }}$ century. With the increase in primary caesarean section there is increase in repeat caesarean section. In India it ranges from 8.48.to $41.9 \%$. $^{1}$ The secondary increase in caesarean section have been associated with increase in obstetric complications including abnormal placentation. 


\section{METHODS}

This is a comparative analysis of two prospective observational studies which were conducted in the Department of Obstetrics and Gynaecology in Seth GS Medical College and KEM Hospital in the year 2003-04 and 2013-14. Patients with two or more previous CS irrespective of parity index, gestational age, previous vaginal delivery or vaginal birth after CS, associated medical or surgical problem, from antenatal outpatient department and emergency patients were included in the study.

A questionnaire was developed that included detailed information regarding maternal age, parity, gestational age, registration status, menstrual and obstetrics history, course of present pregnancy, any medical or surgical history including curettage or myomectomy. Examination findings and relevant investigations including USG obstetrics, with special mention on placental localisation, if any abnormal placentation likes placenta previa or adherent placenta then USG Colour Doppler and MRI findings were documented. Patient diagnosed with the help of radiological investigation like USG / Colour Doppler / MRI or confirmed intraoperative, were taken as abnormal placentation which included placenta previa, morbidly adherent placenta like placenta accreta, placenta increta and placenta percreta.

Vascular interventional radiology procedure like balloon placement and uterine/internal iliac artery embolization if done was documented. Any adjuvant therapy like injection methotrexate given and Beta-hCG levels in such cases was followed up till B-hCG reached the threshold value or patient expelled out the placenta or underwent any surgical intervention. Patients were followed up till discharge from hospital except in case of retained placenta where the follow up was till B-hCG level reached the threshold value, or patient expelled out the placenta or underwent any surgical intervention.

Statistical tool used was SPSS 16.0 version. Descriptive data collected was analysed by mean and standard deviation proportions and the inferential data was by Pearson's Chi Square test and Fischer's exact test.

\section{RESULTS}

Table 1: The distribution of cases.

\begin{tabular}{|lll|}
\hline Total deliveries & $\begin{array}{l}2003-04 \\
(\text { Group 1) }\end{array}$ & $\begin{array}{l}2013-14 \\
\text { (Group 2) }\end{array}$ \\
\hline No. of previous two LSCS & 10,500 & 8000 \\
\hline Percentage & 104 & 60 \\
\hline
\end{tabular}

This study is a prospective comparative analysis of abnormal placentation in patients with previous two caesarean sections admitted to a tertiary care centre in two time periods: From May 2003 to May 2004 and From
May 2013 to May 2014. The distribution of cases is shown in Table 1.

There were $3(2.88 \%)$ placenta previa in the first group out of which $1(0.96 \%)$ was adherent. There were total of 11 abnormal placentation cases in group 2. Total no of placenta previa were 8 and of these $6(10 \%)$ placenta previa had no adherence, remaining 2 were adherent and 3 more adherent placentas were normally situated in the upper segment. So $5(8.3 \%)$ cases of adherent placenta were found. The type of adherence is tabulated in Table 2 below.

Table 2: The type of adherence.

\begin{tabular}{|lll|}
\hline Abnormal Placentation & $\begin{array}{l}\text { 2003-04 } \\
\text { (Group 1) }\end{array}$ & $\begin{array}{l}\text { 2013-14 } \\
\text { (Group 2) }\end{array}$ \\
\hline $\begin{array}{l}\text { Placenta previa without } \\
\text { adherence }\end{array}$ & $2(1.92 \%)$ & $6(10 \%)$ \\
\hline $\begin{array}{l}\text { Placenta previa with } \\
\text { placenta percreta }\end{array}$ & $1(2 \%)$ \\
\hline $\begin{array}{l}\text { Placenta previa with } \\
\text { placenta increta }\end{array}$ & $1(0.96 \%)$ & $1(2 \%)$ \\
\hline $\begin{array}{l}\text { Adherent placenta without } \\
\text { previa (placenta percreta) }\end{array}$ & $3(5 \%)$ \\
\hline
\end{tabular}

All cases of placenta previa were detected antenatally in both the groups. In the first group, the diagnosis of adherent placenta was picked up on imaging while in the second group, one case of adherence could not be investigated as the patient presented in labour with severe antepartum haemorrhage and had to be operated immediately. Out of the remaining 4, 3 were picked up by imaging modalities (USG/ MRI/ Doppler) preoperatively. One case diagnosed as placenta previa on antenatal imaging was found to have associated adherence of placenta percreta intraoperative which was missed in the pre-operative imaging. The distribution of LSCS in both the groups with abnormal placentation is given in Table 3 below.

Table 3: The distribution of LSCS in both the groups with abnormal placentation.

\begin{tabular}{|lllll|}
\hline & $\begin{array}{l}\text { Emergency } \\
\text { LSCS }\end{array}$ & $\begin{array}{l}\text { Elective } \\
\text { LSCS }\end{array}$ & $\begin{array}{l}\text { Term } \\
\text { LSCS }\end{array}$ & $\begin{array}{l}\text { Pre- } \\
\text { term } \\
\text { LSCS }\end{array}$ \\
\hline $\begin{array}{l}\text { 2003-04 } \\
\text { (Group 1) }\end{array}$ & 2 & 1 & 1 & 2 \\
\hline $\begin{array}{l}\text { 2013-14 } \\
\text { (Group 2) }\end{array}$ & 9 & 2 & 4 & 7 \\
\hline
\end{tabular}

Even though all patients would have been sectioned electively, this did not happen as patients either started bleeding or went into labour before term as seen in Table 3. 
Among cases of abnormal placentation in Group 1, in 2 cases $(66.66 \%)$ placenta was completely removed while in Group 2, in 6 cases $(54.5 \%)$ placenta could be completely removed. One case in Group 1 (33.33\%) required obstetric hysterectomy for adherent placenta whereas two cases (18.18\%) required it in Group 2. In the remaining 3 patients with adherent placenta in Group 2, placenta was kept in situ and post-operative methotrexate therapy was given along with serial B-HCG monitoring. Classical section was planned in these 3 cases. Cord was ligated at its insertion and no attempt was made to separate the placenta.

Among cases of abnormal placentation in Group 1, two cases $(66.66 \%)$ required haemostatic sutures while 5 cases $(45.45 \%)$ required haemostatic sutures in group 2 . Out of the 5 cases in Group 2, all 5 required uterine artery ligation and 2 cases required both uterine and internal iliac ligation. Preoperative balloon placement was done in 3 cases in internal iliac artery and one case in uterine artery. Among cases of abnormal placentation in Group 1,2 cases $(66.66 \%)$ required blood transfusion while in Group 2, $9(81.81 \%)$ required transfusion.

One neonate required NICU admission in group 1 with abnormal placentation, while 5 neonates required admission in group 2 with abnormal placentation.

The neonatal outcome in terms of birth weight in patients with abnormal placentation is tabulated in Table 4 below.

There were no maternal mortalities in both the groups.

Table 4: The neonatal outcome in terms of birth weight in patients with abnormal placentation.

\begin{tabular}{|c|c|c|}
\hline $\begin{array}{l}\text { Birth weight } \\
\text { (gms) }\end{array}$ & $\begin{array}{l}\text { 2003-04 } \\
\text { (Group 1) }\end{array}$ & $\begin{array}{l}\text { 2013-14 } \\
\text { (Group 2) }\end{array}$ \\
\hline$<1500$ & 1 & 2 \\
\hline 1500-1999 & 0 & 4 \\
\hline $2000-2499$ & 2 & 2 \\
\hline $2500-2999$ & 0 & 2 \\
\hline$>3000$ & 0 & 1 \\
\hline
\end{tabular}

\section{DISCUSSION}

Our data compares 104 cases of women with previous two or more Caesarean section during 2003-04 with 60 women with previous two or more Caesarean section during 2013-14 for their placentation along with maternal and fetal outcomes. This study was a prospective comparative study in which entire antenatal course since first registration to delivery, radiological data, intraoperative and postoperative complications was available for records. Most of the similar studies were retrospective studies.

The higher incidence of abnormal placentation in group 2 of our study could be attributed to the fact that ours being a tertiary care centre, patients were referred to our institute as MRI and interventional radiology services were started and became freely available. The reason for decline in absolute number of women with previous two Caesarean section could be attributed to the fact that women had started opting for smaller families and the family planning services were better accepted.

In our study, whereas obstetric hysterectomy was the modality of treatment in group 1, interventional radiology procedure was done in $27.3 \%$ of patients of which preoperative internal iliac artery balloon placement was done in $18.1 \%$ of cases and uterine artery balloon placement in $9 \%$ of cases amongst the abnormal placentation in Group 2.

In our study amongst abnormal placentation cases, in group 1, 33.33\% required obstetric hysterectomy while in group 2 only $18.18 \%$ required it, uterine artery ligation was done in $45.45 \%$ of patients and $18.2 \%$ required internal iliac ligation. As per Rashid $\mathrm{M}$ et al 25\%, Nisenbalt $\mathrm{V}$ et al $11 \%$ and Robert M. Silver et al $22 \%$ required obstetrics hysterectomy. ${ }^{2-4}$ Our study showed higher rates compared to all the above studies, although the rates are falling due to advent of conservative techniques in management of adherent placenta. As per study by AF Hundley, $90 \%$ of women were successfully managed with conservative treatment using methotrexate therapy. ${ }^{5}$

In this study, mean birth weight was $2.230 \mathrm{~kg}$ in group 1 and $2.790 \mathrm{~kg}$ in group 2. This is similar to birth weights by Sobande $\mathrm{A}$ and Rashid $\mathrm{M}$ et al where mean birth weight were $2.972 \mathrm{~kg}$ and $2.966 \mathrm{~kg}$ respectively. ${ }^{2,6}$ Birth weights were lower compared to study by Macones GA and Cahill AG et al in which mean birth weight was $3.392 \mathrm{~kg}$ and $3.046 \mathrm{~kg}$ respectively. ${ }^{7,8}$ Lower birth weight can be explained by the fact that the patients in our country are constitutionally small as compared to their western counterparts along with anaemia, preeclampsia, abnormal placentation and multitude of social problems.

In our study, $33.33 \%$ neonates required NICU admission in group 1 whereas $45.45 \%$ required it in group 2. In study by Rashid $\mathrm{M}$ et al $4 \%$ required resuscitation and $20 \%$ NICU admission. ${ }^{2}$

From this study we conclude that although the absolute number of women with previous two caesarean section has reduced due to better family planning services, the rate of abnormal placentation has increased. In this study due to lack of previous operative notes, or incomplete documentation in the previous operative notes we could not assess other concomitant factors responsible for abnormal placentation. Hence, details like type of closure, suture material and other significant intraoperative findings could not be studied. This calls for a detailed assessment of these cases for these factors to establish or refute a causative relationship with incidence of abnormal placentation. 


\section{AKNOWLEDGEMENT}

I would like to express my heartfelt gratitude to my parents, teachers and friends who guided me throughout the study. I would also like to express my gratitude to Dr. S. V. Parulekar, head of department of Obstetrics and Gynecology at KEM Hospital for his iron support.

I would like to make a special mention to Dr Laxmi Laud for her support that has made my study successful.

Funding: No funding sources Conflict of interest: None declared

Ethical approval: The study was approved by the Institutional Ethics Committee

\section{REFERENCES}

1. Chhabra S, Arora G. Delivery in women with previous Caesarean section. J Obstet Gynecol India. 2006;56(4):304-7.

2. Rashid M, Rabia S. Rashid. Higher order repeat Caesarean sections: how safe are five or more? RCOG. 2004;111:1090-4.
3. Nisenbalt V, Barak S, Griness OB. Maternal complications associated with multiple Caesarean deliveries. Obstet Gynecol. 2006;108:21-6.

4. Silver RM, Landon MB, Rouse DJ. Maternal morbidity associated with multiple Caesarean deliveries. Obstet Gynecol. 2006;207:1226.

5. Hundley AF, Parrotz L. Managing placenta accreta. OBG management. 2002;8:18-33.

6. Sobande A, Eskandar M. Multiple repeat Caesarean sections: complications and outcomes. Canada: JOGC 04. 2006;28(3):193-7.

7. Macones GA, Cahil A, Pare E. Obstetrics outcomes in women with two prior Caesarean deliveries: Is vaginal birth after Caesarean delivery a viable option? Am J Obstet Gynecol. 2005;192:1223-39.

8. Cahill AG, Tuuli M, Odibo AO, Stamilio DM, Macones GA. Vaginal birth after Caesarean for women with three or more prior Caesarean s: assessing safety and success. BJOG. 2009;117:4228 .

Cite this article as: Poonia S, Pandey N, Gupta A. Comparative study of abnormal placentation in patients with previous two caesarean section over two time periods. Int J Reprod Contracept Obstet Gynecol 2016;5:3879-82. 